УДК 159.9:616.89

\title{
ОРГАНИЗАЦИОННО-МЕТОДОЛОГИЧЕСКИЕ ОСНОВЫ СИСТЕМЫ ПСИХОЛОГИЧЕСКОЙ РЕАБИЛИТАЦИИ В КОНТЕКСТЕ КОНЦЕПЦИИ «ВНУТРЕННЕЙ КАРТИНЫ ИНВАЛИДНОСТИ"
}

\author{
Рыбников Виктор Юрьевич \\ Морозова Елена Валерьевна
}

В статье представлены результаты исследования, продолжающего серию научных разработок конструкта «Внутренняя картина инвалидности», целью которых является совершенствование реабилитационных подходов в плане повышения приверженности к реабилитации в рамках психологической парадигмы и реабилитационном контексте в целом.

В статье обобщены результаты исследования личностной, адаптационной реакции больных на ситуацию инвалидизирующего заболевания вследствие социально-экономических и психофизиологических последствий болезни. В исследовании принимали участие больные основных инвалидизирующих патологий $(n=510)$, формирующих ведущие позиции в структуре инвалидности Российской Федерации. Статистическая обработка совокупности психологических параметров позволила оченить структуру психологической переработки больным ситуации инвалидизирующего заболевания в контексте реабилитационной готовности к преодолению возникающих последствий болезни.

Исследование выявило специфику реабилитационной активности, которая характеризуется различной степенью включенности психологических ресурсов в зависимости от степени фрустрации. Незначительная фрустрачия характеризуется в большей степени психологической фиксацией на болезни, далее нарастание фрустрации потенцирует больного к большей вариативности адаптационного поведения со смещением реагирования с фокуса негативных последствий заболевания к личностному самоопределению, рефлексии личностных ченностей и смыслов. Выраженная степень фрустрации блокирует реабилитационную активность, проявляясь "хаотичным» характером реакций с уходом от рефлексивного компонента в преобладание дезадаптивных «эмоциональных» стратегий. Исследование выявило основные реабилитационные "маркеры», характеризующие личностный реабилитационный потенциал и реабилитационный прогноз для эффективного формирования индивидуальной программы реабилитации больных. 
Предложена модель системы психологической реабилитации в контексте концепции «Внутренней картины инвалидности», раскрыты ее организационные и процессуально-методологические аспекты, с указанием целей, принципов, условий, критериев эффективного реабилитационного исхода, последовательности проведения реабилитачионных мероприятий и существующих проблем в эффективной реализации реабилитации больных на различных этапах заболевания (до инвалидизачии, в прочессе пребывания на инвалидности и после ее утраты), с указанием возможных практик повышения эффективности психологической реабилитации больных.

Ключевые слова: внутренняя картина инвалидности, приверженность реабилитации, реабилитационная готовность, реабилитационный потенииал, реабилитационные маркеры, психологическая адаптация, совладающее поведение, инвалидность, лиминальность, социальная фрустрация.

\section{Введение}

Несмотря на достигнутую стабилизацию показателей инвалидизации населения Российской Федерации и отсутствие ее роста с 2014 г., проблема инвалидности является по-прежнему актуальной. Количество инвалидов, нуждающихся в реабилитации, проживающих в нашей стране, сложная экономическая ситуация вследствие общемирового политического кризиса представляют собой факторы риска в отношении возможных последствий ухудшения положения инвалидов. Изложенное обусловливает необходимость разработки антикризисных программ, направленных на повышение эффективности реабилитационных подходов, сфокусировав внимание на инвалидизирующих патологиях, формирующих основную структуру инвалидности в нашей стране. За последнее время исследования различных аспектов инвалидности и разработки в области оказания эффективных форм реабилитации существенно обогатили представления о данной междисциплинарной категории [1, 2, 3, 4, 5, 6, 7, 8, 18, 20-30].

Однако далеко не все теоретические и практические вопросы в данной области решены. По-прежнему остаются неразрешенными проблемы и противоречия, возникающие у человека, порождаемые инвалидностью как социальным феноменом. В том числе недостаточно изучены проблемы, непосредственно касающиеся психологии инвалидизирующейся личности. В прикладном отношении эти противоречия и проблемы охватывают не только индивидуально-психологический уровень каждого конкретного человека, находящегося на различных этапах инвалидизирующего заболевания, но и ближайшее окружение и социум в целом, что обусловливает высокий социально значимый контекст данной проблемы, решать которую необходимо 
в том числе в рамках медицинской психологии, разрабатывая эффективные модели психологической реабилитации больных.

Проблема инвалидности с психологической точки зрения, по нашему мнению, заключается в том, что при всех позитивных изменениях в сфере бурного развития медицинских технологий, обеспечивающих положительные исходы реабилитации, вследствие функционального улучшения, отчетливо наблюдается «обратная сторона медали» социально-психологической природы. Проявляется это в виде различных личностных реакций, порождающих специфические виды социального поведения, затрудняющие социализацию больного в условиях потенциально инвалидизирующего заболевания.

Социализация больных вследствие тяжелых заболеваний всегда сложна в большинстве сфер жизнедеятельности, что позволяет категоризировать текущий этап жизни человека как «трудную жизненную ситуацию».

Однако особую проблему в социально-психологическом смысле представляют так называемые «переходные» жизненные ситуации, обусловленные динамическими изменениями статуса (в частности, связанного с инвалидностью как в случае ее первичного установления, так и утраты), требующие от больного личностной трансформации и активизации внутренних приспособительных резервов - личностного потенциала, за счет использования которого больной способен адаптироваться к условиям изменяющейся действительности.

Происходит данная трансформация под влиянием субъективно сформированного отношения к инвалидности и к себе как к инвалиду (т. е. внутренней картины инвалидности) $[9,10,13]$, либо под влиянием отношения к себе как к больному (т. е. в рамках внутренней картины болезни) без идентификации со статусом «инвалид».

Данная проблема является ключевой в плане эффективного исхода реабилитации в целом, т. к. структурные компоненты данного субъективного личностного образования «Внутренней картины инвалидности» фактически отражают психологическую (личностную) готовность к реабилитационной активности либо тенденцию к уходу в инвалидизацию и пассивноиждивенческому приспособлению [17].

Личностное самоопределение больного в преддверии выбора между обращением в государственное учреждение медико-социальной экспертизы за инвалидностью или жизнью в условиях инвалидизирующего заболевания без данного статуса (т. е. непринятие себя в роли инвалида) - одна из сложнейших проблем, психологически затрагивающих все стороны жизни человека в сложившейся ситуации развития, которую справедливо можно охарактеризовать как «кризисную». 
Авторы философских исследований указывают, что такие ситуации «выбора» и личностного самоопределения в период различных кризисов могут рассматриваться в рамках «лиминальных» состояний (прохождение границ - от лат. «limen» - порог и «переход» в иное качество). Связано это с возможным изменением социального статуса, ценностей и норм, идентичности и самосознания, следствием чего является широкий спектр экономических, социологических, психологических и физиологических проблем, задача преодоления которых возникает перед личностью в рамках различных кризисных периодов. Концепция «лиминальности» вполне применима к личностному самоопределению в период адаптации больного к инвалидизирующему заболеванию на всех его этапах (до инвалидизации, в процессе пребывания на инвалидности, а также для реабилитированных больных, утративших в результате положительного исхода реабилитации статус «инвалид»). Интересен феномен «лиминальности» как личностного переходного состояния своим потенциалом, во многом предопределенным природой лиминальности (ситуацией «нестабильности», «амбивалентности», «размытой социальной идентичности» и др.), активно стимулирующей личность на энергичный поиск качественно новых стратегий адаптации.

В традиции отечественной клинической психологии в отношении реабилитации больного, находящегося в условиях инвалидизирующего заболевания, исторически признавалась высокая значимость роли личности в реабилитационном процессе. В одной из последних монографий отечественный психолог К. К. Платонов подчеркивал необходимость реабилитации личности больного [16]. В российском законодательстве понятие «реабилитация инвалидов» на данном этапе регламентировано Федеральным Законом № 181 «О социальной защите инвалидов в Российской Федерации» (в редакции Федерального закона от 01.12.2014 № 419-Ф3), определение представлено в следующей трактовке: «...Реабилитация инвалидов - система и процесс полного или частичного восстановления способностей инвалидов к бытовой, общественной, профессиональной и иной деятельности... Реабилитация и абилитация инвалидов направлены на устранение или возможно более полную компенсацию ограничений жизнедеятельности инвалидов в целях их социальной адаптации, включая достижение ими материальной независимости и интеграции в общество...». Тем же законодательным актом психологическая реабилитация, наряду с другими видами реабилитации, определена как реабилитационное направление. В Индивидуальной программе реабилитации и абилитации инвалида (ребенка-инвалида), фактически являющейся механизмом реализации реабилитации, мероприятия по психологической реабилитации включены в раздел социальной реабилитации. 


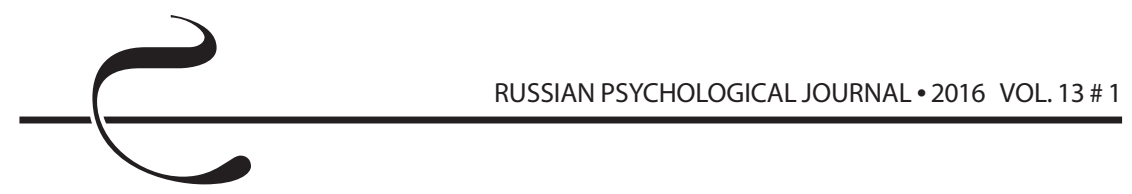

Однако на сегодняшний день существующее законодательство интенсивно меняется, пересматриваются форма Индивидуальной программы реабилитации и абилитации, механизмы ее реализации на межведомственной основе. Учитывая важность создания четких координат реабилитационной направленности, для эффективного решения проблемы организации психологической реабилитации личности нами предлагается многокомпонентная методологическая модель реабилитации в контексте концепции «Внутренней картины инвалидности», интегрирующая в своем содержании все необходимые для построения моделей структурные параметры.

Представленная на рисунке 1 модель отражает содержание общих концептуальных компонентов системы психологической реабилитации в контексте концепции «Внутренней картины инвалидности» (ВКИ) с учетом нормативно-правовой составляющей, теоретико-методологического компонента (включая цель, задачи, основные принципы, подходы, условия и критерии эффективной реализации реабилитационного процесса). Основная цель психологической реабилитации больных, находящихся на различных этапах инвалидизирующего заболевания - повышение реабилитационной приверженности (активности и участия больного в различных жизненных и социальных сферах с целью их интеграции в общество и социальнопсихологической адаптации), а также профилактика пассивно-иждивенческого приспособления (ухода в инвалидизацию).

Для реализации данной цели необходимо оценить реабилитационную готовность личности к активному восстановлению, а также выявить реабилитационные диспозиции «мишени», непосредственно влияя на которые в процессе реабилитации возможно повышение реабилитационной приверженности. Следствием повышения реабилитационной приверженности является достижение положительных исходов реабилитации, сформулированных в предлагаемой модели на основании эмпирических данных, полученных в ходе исследований адаптации больных на различных этапах инвалидизирующего заболевания $[11,12]$.

Далее в статье рассматриваются обобщенные данные, характеризующие различный уровень реабилитационной готовности больных, адаптирующихся к инвалидизирующему заболеванию в различных жизненных ситуациях (при наличии инвалидности и вне данного статуса).

Цель статьи - обоснование модели психологической реабилитации в контексте концепции «Внутренней картины инвалидности» (ВКИ) на основе эмпирического изучения динамических изменений ее параметров, характеризующих реабилитационный потенциал больного, в зависимости от степени социально-стрессового воздействия на личность (социальной фрустрации) вследствие инвалидизирующего заболевания. 


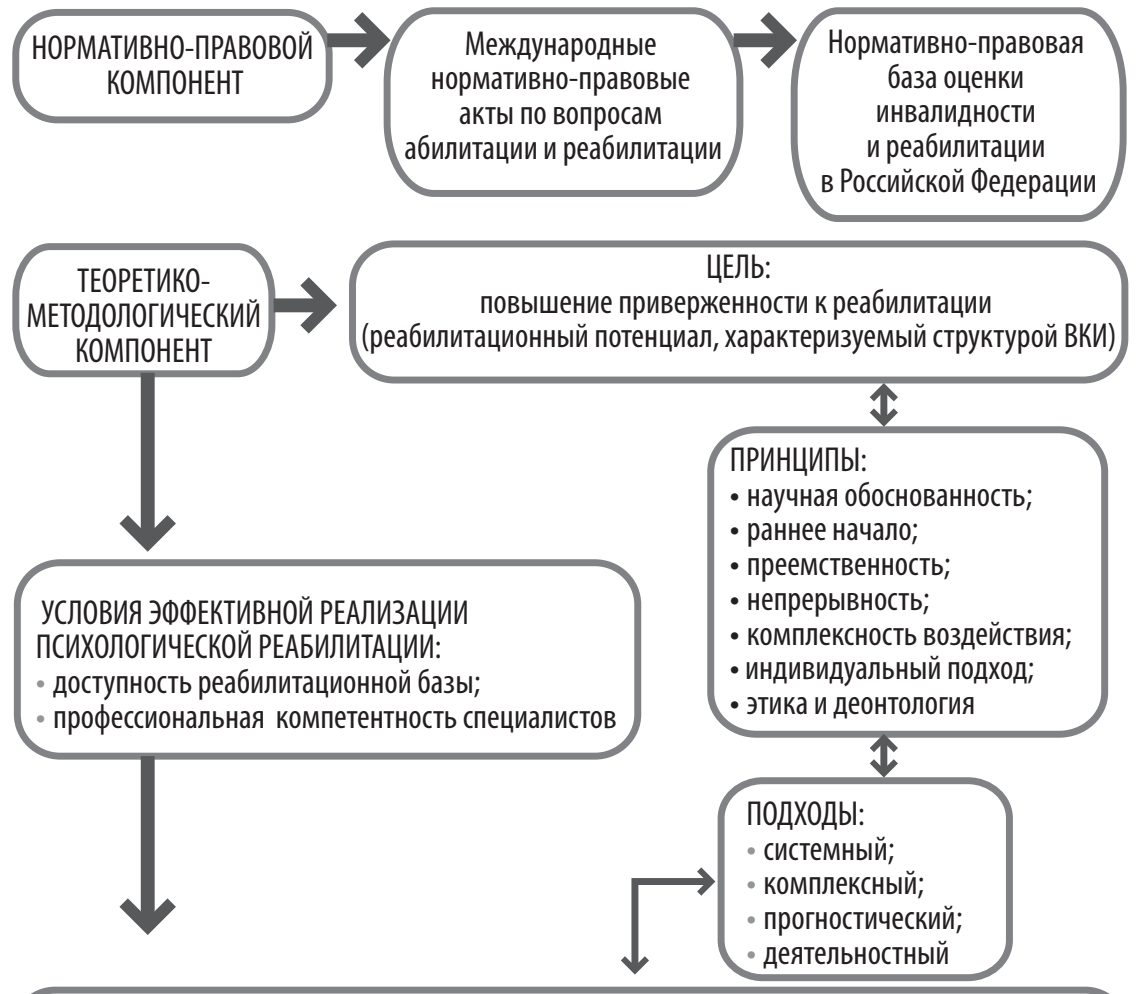

Психологические критерии положительного исхода реабилитации:

- максимальная ориентация на использование собственных (внутриличностных) ресурсов и возможностей;

- ориентация на планомерное выполнение медицинских рекомендаций по лечению и поддержанию здоровья, режима питания, отдыха и активности;

- понимание хронической природы заболевания и обратимости категории "инвалидность" в условиях полной и частичной реабилитации, достигающей функциональной компенсации; - посильная активность и участие (интеграция) в социальных, межличностных взаимодействиях, профессиональная включенность и достижение экономической независимости; экзистенциальное значение болезни как "вызов" на пути развития личности

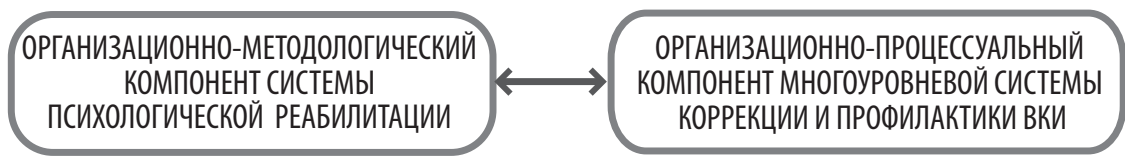

Рисунок 1. Общая (многокомпонентная) модель системы психологической реабилитации в контексте концепции «Внутренней картины инвалидности» 
Нами было предпринято исследование реакции личности на социальнострессовую ситуацию, возникающую в связи с инвалидизирующим заболеванием, вызывающую необходимость активного использования реабилитационного потенциала, характеризующегося психологическими структурными параметрами «Внутренней картины инвалидности».

Исследовались больные, впервые претендующие на статус «инвалид», либо имеющие инвалидность и претендующие на утяжеление ее степени или ее возврат в случае смены статуса в связи с полной реабилитацией (утратой инвалидности), а также больные, объективно имеющие показания к инвалидности, но не причисляющие себя к данной социально-демографической категории, адаптирующиеся в условиях инвалидизирующего заболевания, полагаясь на собственную систему ресурсов. Непосредственным эмпирическим материалом для обобщений стало сопоставление трех групп испытуемых, различающихся по степени переживания социальной фрустрированности.

\section{Материалы и методы}

Обследовали 510 больных: находящихся на этапе медико-социальной экспертизы по поводу оценки инвалидности в ФГБУ ФБ МСЭ Минтруда России $(n=420)$ и больных, находящихся в клинике ФГБУ ФБ МСЭ Минтруда России $(\mathrm{n}=90)$ на этапе реабилитационно-восстановительного лечения вследствие различных заболеваний, формирующих основную структуру инвалидности в России. Из них - больных с заболеваниями вследствие болезней сердца и кровообращения $(n=130)$, заболеваниями вследствие злокачественных новообразований $(\mathrm{n}=105)$, заболеваниями вследствие нарушений костно-мышечной системы и соединительной ткани ( $\mathrm{n}=90)$, заболеваниями вследствие хронической эндокринной патологии - сахарный диабет 1-го $(n=90)$ и 2-го $(n=95)$ типов. По степени выраженности социальной фрустрированности (опросник самоотчета Л. И. Вассермана) обследуемые были разделены на три равные группы (с незначительной, умеренной и выраженной степенями фрустрированности; статистически значимые межгрупповые различия подтверждены на уровне $\mathrm{p}<0,01$ ).

В исследовании применялся комплекс диагностических средств, оценивающих как показатели социальной фрустрированности, так и индивидуальнопсихологические особенности реакции больных на складывающуюся новую социальную ситуацию, необходимость адаптации к которой диктуется психофизиологическими, экономическими и социальными последствиями болезни. Использовались следующие методики: «Медико-социологический опросник диагностики уровня социальной фрустрированности (УСФ)», разработанный Л. И. Вассерманом; «Шкала оценки выраженности копингмеханизмов» Э. Хайма (Е. Неim), адаптированная в Санкт-Петербургском 
научно-исследовательском институте им. В. М. Бехтерева; опросник «Индекс жизненного стиля» (life style index), выявляющий степень напряженности защитных личностных механизмов, адаптированный в Санкт-Петербургском научно-исследовательском институте им. В. М. Бехтерева; опросник «Двадцать утверждений» (М. Кун и Т. Макпартлэнд) для изучения структуры личностной и социальной идентичности методом ответа на вопрос «Кто Я?» (обработка в модификации шкалы Н. Л. Ивановой - Т. В. Румянцевой); «Опросник ценностно-смысловых ориентаций» С. С. Бубновой (Институт психологии Российской академии наук (ИПРАН); шкала Т. Дембо - С. Я. Рубинштейн для исследования самооценки больным своих личностных качеств и состояний; «Клинико-диагностический опросник» А. И. Сердюка для исследования психофизиологических и различных социальных последствий, возникающих вследствие заболевания. Статистическая обработка результатов исследования, приводимых в публикации, проводилась с применением непараметрического критерия Манна-Уитни и регрессионного анализа.

\section{Результаты и их анализ}

В ходе эмпирического исследования изучено 106 психологических параметров, характеризующих адаптацию каждого из обследованных, которые были обобщены с помощью регрессионного анализа и представлены в виде следующих сегментограмм (см. рисунки 2-4).

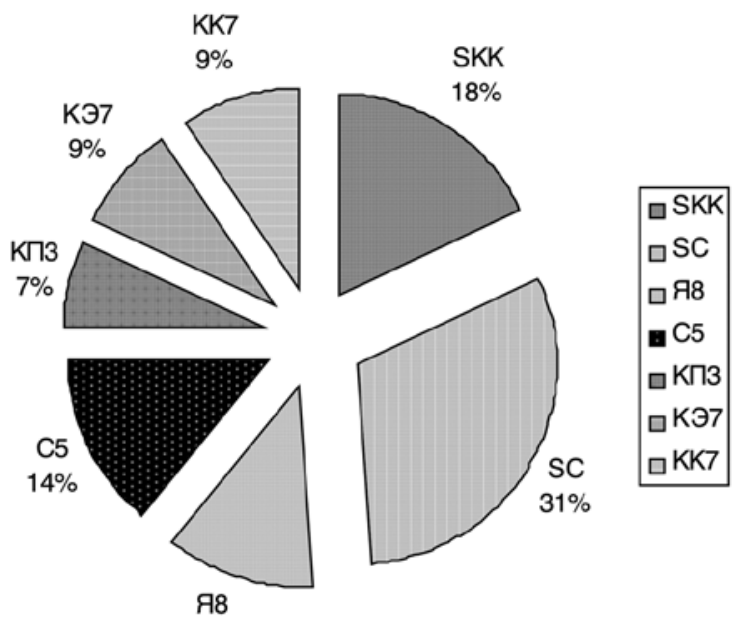

Рисунок 2. Сегментограмма по результатам регрессионного анализа 1-й группы обследованных (низкие показатели выраженности социальной фрустрированности по Л. И. Вассерману). Комментарии в тексте 


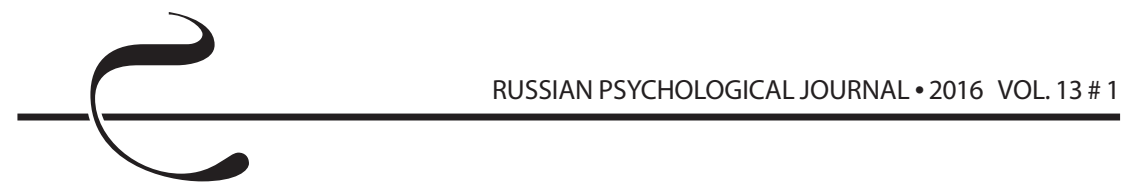

Резюмируя полученные результаты, мы можем утверждать, что первой реакцией на фрустрацию, определяемую угрозой инвалидизации, является рефлексия своего статуса. Прежде всего этот статус проецируется на социальное окружение, человек переопределяется в привычной социальной среде, подстраиваясь под возникающие изменения. Во второй группе (при умеренном нарастании фрустрационных переживаний) выявлены следующие характеристики (рисунок 3):

1. Наибольший вес, с подавляющим преимуществом - занимают переживания, отражающие самооценку личностью своих индивидуальнопсихологических параметров и состояний, 70 \% из которых представляют следующие конкретные характеристики: S9 - 20 \% - осознание самоэффективности в сфере «трудоспособность»; самоэффективность в эмоциональной сфере S8 - 18 \% - «контроль поведения»; самоэффективность в быту S7 - 17 \% - «способность к самобослуживанию»; в сфере межличностных и социальных отношений в целом S10 - 15 \% - «способность к общению».

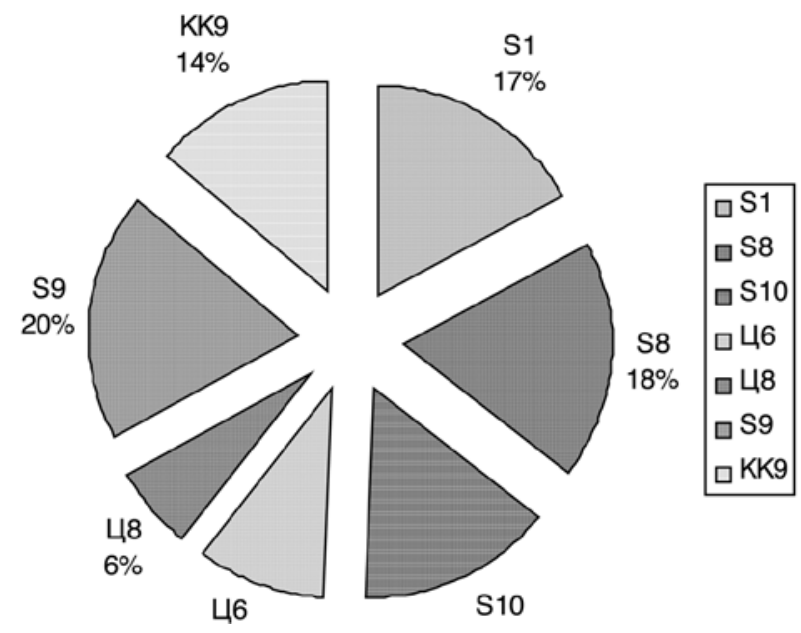

Рисунок 3. Сегментограмма по результатам регрессионного анализа

2-й группы обследованных (умеренные показатели выраженности социальной фрустрированности по Л. И. Вассерману). Комментарии в тексте

2. Второе место - $16 \%$ - занимают проблемы ценностных ориентаций (Ц6 - $10 \%$ - значимость смысловой категории в системе ценностей познавательного уровня «открытие нового»; Ц8 - $6 \%$ - значимость смысловой 
категории в системе ценностей - социальных аспектов межличностных взаимоотношений «признание людей и влияние на окружающих»).

3. Третье место - 14 \% - занимает такой вид копинг-стратегий, как приверженность к когнитивному стилю совладающих стратегий - «диссимиляция, недооценка проблемы».

По сравнению с первой группой больных (незначительно переживающих социальную фрустрацию вследствие инвалидизирующих заболеваний), в данной группе (где переживание фрустрации увеличивается до умеренной степени) акценты личностных реакций смещаются с фокуса «социальной значимости болезни» к более личностным реакциям самоопределения, от широкого поиска стратегий поведения к рефлексии личностных ценностей, от самоопределения - к, пусть временному, дистанцированию от возникающих адаптационных проблем. В организационном смысле в реабилитационной работе на этом этапе становится очевидной необходимость включения различных видов и форм психологической реабилитации с целью мобилизации внутриличностных (психологических) адаптационных резервов, повышающих активность и участие больного в процессе реабилитации.

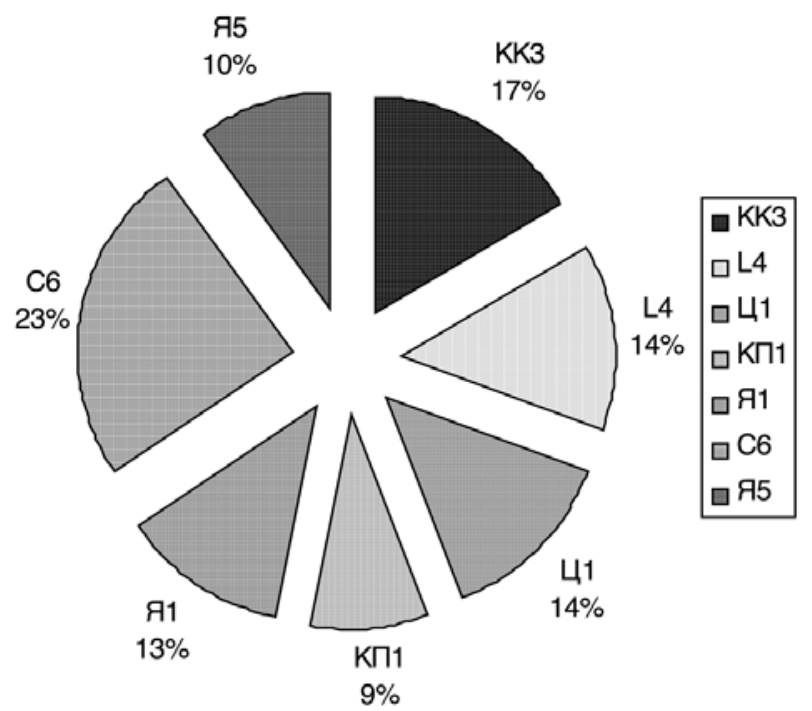

Рисунок 4. Сегментограмма, построенная по результатам регрессионного анализа 3-й группы обследованных (высокие показатели выраженности социальной фрустрированности по Л. И. Вассерману). Комментарии в тексте 
В регрессионном анализе показателей третьей группы (переживающих значительную социальную фрустрацию) мы можем выделить уже 5 блоков характеристик, отражающих приспособительную реакцию выраженно фрустрированных вследствие заболевания больных (рисунок 4):

1. Первое место с $26 \%$ занимают характеристики копинг-компетентности в виде копинг-стратегии (на смену «поискам смысла» и «диссимиляции» приходит «когнитивная» копинг-стратегия ККЗ - 17 \% - «сохранение самообладания», характеризующая следующий вид психологической переработки - «...я не теряю самообладания и контроля над собой в тяжелые минуты и стараюсь не показывать своего состояния...», а также когнитивная стратегия КK1 - 9 \% - «смирение»).

2. На втором месте - $23 \%$ - «самоидентификационные характеристики личности» (13\% - Я1 - «рефлексия социального Я»; $10 \%$ - Я5 - «рефлексия деятельностного Я»).

3. На третьем месте - 23 \% - субшкала С6, характеризующая субъективное эмоциональное переживание социальных последствий заболевания (опросник А. И. Сердюка) - «ограничение карьерного роста».

4. На четвертом-пятом местах по $14 \%$ : L4 - механизм психологической защиты личности «компенсация» и Ц1 - значимость в системе ценностей возможности получать «удовольствие и отдых».

Резюмируя результаты психологических характеристик наиболее фрустрированных больных, составляющих третью группу, можно сказать, что общий характер реагирования на выраженную стрессовую ситуацию характеризуется некой «дезинтеграцией», что неизбежно ведет к переживанию беспомощности, растерянности и, как следствие, порождает нуждаемость в развернутом комплексном подходе по оказанию психологической помощи для данной категории больных.

Соотнося полученные результаты эмпирического исследования с общей концепцией системы психологической реабилитации (с учетом ее цели, условий, задач достижения ее положительного исхода и принципов организации), необходимо констатировать следующее:

1. Увеличение «уровня социальной фрустрированности», которое мы фиксируем по реакции испытуемого (самоотчету) на самый широкий спектр социальных связей личности, тесно связано с выраженными изменениями в психологической регуляции деятельности (реабилитационной активности, под которой следует понимать степень приверженности к реабилитации).

2. К наиболее значимым изменениям можно отнести выраженное повышение всех без исключения показателей опросника социальной фрустрированности (опросника А. И. Сердюка), тесно связывающих 
возникающие у больных переживания и социальные эффекты вследствие различных проявлений заболевания. После относительно медленного роста показателей при переходе от первой группы ко второй, выраженное повышение переживаний социального неблагополучия отмечается у больных в третьей группе (которое, в свою очередь, начинает выступать системообразующим фактором в формировании отношения к окружающему и к себе в ситуации необходимости адаптации к инвалидизирующему заболеванию).

3. Анализ показателей совладания с ситуацией инвалидизирующего заболевания (психологических защит и копинг-стратегий) обнаруживает следующие характерные закономерности:

3.1. Психологические защиты активно участвуют в переработке ситуации на первом этапе нарастания фрустрационных переживаний, их сила в дальнейшем несколько ослабевает.

3.2. Поиск самых разнообразных копинг-стратегий также преимущественно локализуется на первых этапах. Начальный этап в основном представлен «когнитивными» и «поведенческими» стратегиями (по шкале Э. Хайма), в то время как на третьем этапе доминируют более дезадаптивные «эмоциональные» копинг-механизмы, не способствующие положительному исходу адаптации, характеризуя низкую реабилитационную готовность личности.

4. Самооценка трех групп обследуемых также во многом отражает уровень социальной фрустрированности следующим образом - чем выше уровень фрустрированности, тем ниже самооценка личностью больного своих индивидуально-психологических качеств и собственной эффективности в осуществлении различных сфер жизнедеятельности. Другими словами, для эффективной реабилитационной работы (с опорой на самостоятельную активность личности) необходима массированная психокоррекционная работа на всех этапах переживания инвалидности (или тяжелого соматического неблагополучия, грозящего инвалидностью).

5. Относительно более устойчивыми характеристиками в процессе проживания и адаптации к ситуации инвалидизирующего заболевания являются внутриличностные ценностно-смысловые установки и структурные компоненты идентичности (самоидентификация), что может (и на наш взгляд, должно) стать основой личностно-ориентированной реабилитационной работы с больными.

С одной стороны, данные характеристики не могут избежать деформирующего влияния нарастающей социальной фрустрированности, но с другой стороны, они демонстрируют относительную устойчивость (при наличии их 
сформированности на предыдущих этапах социализации). Важно, что такой показатель, как «рефлексивное Я» повышается от первой группы ко второй и только потом начинает снижаться, что значительно смягчает психологическую картину ухудшения состояния.

6. При регрессионном анализе результатов обнаруживается, что для первого этапа адаптации больных с незначительной фрустрированностью вследствие заболевания в наибольшей степени характерна фиксация на болезни, для второго этапа - на себе, третий этап адаптации с более выраженной фрустрированностью представлен значительным разнообразием вариантов поведения (хотя и при доминировании сильных отрицательных эмоциональных переживаний).

7. Полученные психометрические показатели в ходе диагностики больных всех исследуемых групп характеризуют основные структурные «маркеры» реабилитационного прогноза в контексте личностной модели «Внутренней картины инвалидности», определяя реабилитационные диспозиции «мишени», позволяющие прицельно влиять на коррекцию и профилактику дезадаптивных форм адаптации больного на всех этапах инвалидизирующего заболевания.

8. Качественные характеристики адаптационных параметров, полученные в исследовании, свидетельствуют об очевидной необходимости включения специалистов-психологов для обеспечения мероприятий по психологической реабилитации (коррекции и / или профилактики дезадаптивных проявлений внутренней картины инвалидности) для больных на всех этапах адаптации к инвалидизирующему заболе-

ванию в зависимости от специфики и степени проявленности обнаруженных на диагностическом этапе реабилитационных диспозиций.

Далее раскроем более подробно содержание организационнометодологического и организационно-процессуального компонентов представленной ранее реабилитационной модели (см. рисунки 5, 6), непосредственно отражающих практический механизм реализации системы психологической реабилитации как таковой.

На рисунке 5 изложена структура организационно-методологического компонента системы психологической реабилитации.

В схеме представлен порядок действий (интервенций), осуществлять которые необходимо с учетом следующих этапов реализации реабилитационного процесса (диагностического и коррекционно-профилактического), в соответствии с намеченной целью, задачами, методами и предлагаемыми возможными формами. В данной схеме, на этапе диагностической задачи по оценке стурктурных компонентов «Внутренней картины инвалидности», представлены психологические параметры, являющиеся объектом диагностического исследования для 
целей реализации реабилитационного процесса. Данные параметры, с одной стороны, характеризуют реабилитационный потенциал личности (личностный ресурс), опираясь на сохранные звенья которого и должен строиться реабилитационный процесс. С другой стороны, структурные компоненты «Внутренней картины инвалидности» отражают (в зависимости от степени «повреждения», недоразвития, нарушения) «маркеры» реабилитационного прогноза, также являясь реабилитационными диспозициями, т. е. непосредственными «мишенями», прицельное воздействие на которые позволит адресно корригировать (формировать, развивать) приверженность к реабилитации, повышая вероятность положительного реабилитационного исхода.

Развитием данной схемы явлется рисунок 6, в котором отражены принципиальные этапы для реабилитационного воздействия и механизмы его реализации (с указанием исполнительных органов) в соответствии с динамикой инвалидизирующего заболевания (до установления группы инвалидности, в процессе пребывания на инвалидности и после полной реабилитации в связи с утратой статуса «инвалид»). Предлагаемая структурная схема организации реабилитационного процесса позволяет наглядно отследить степень эффективной действенности механизма его реализации, который на данном этапе законодательно «фиксирован» и исполняется лишь в процессе пребывания больного в зоне инвалидизации, реализуясь посредством Индивидуальной программы реабилитации или абилитации инвалида (далее ИПРА), являющейся обязательной для исполняющего органа.

Данный факт означает принципиальный аспект - для инвалида Индивидуальная программа реабилитации и абилитации является рекомендательной для исполнения.

Именно личностная готовность к реабилитации, т. е. психологическая приверженность, стимулирует больного обращаться и использовать имеющийся в его арсенале механизм в виде ИПРА для получения психологической помощи, поддержки и др.

Исходя из законодательно установленного порядка реализации ИПРА инвалид может обратиться в исполнительные органы за получением определенных реабилитационных мероприятий (в данном случае психологической направленности), а может не обращаться при отсутствии мотивации к реабилитации. В то время как для органа, исполняющего указания службы медико-социальной экспертизы о необходимости включения в реабилитацию больного мероприятий по психологической реабилитации (коррекции внутренней картины болезни и инвалидности и др.), данные указания являются обязательными к исполнению, и учреждение, в которое инвалид направлен, обязано данные мероприятия реализовать. В остальных случаях механизм реализации реабилитационного процесса больных практически не имеет 
регулирования. А именно, на этапе адаптации больного до законодательно установленной инвалидности, а также в случае полной реабилитации (когда в результате функциональной компенсации и восстановления группа инвалидности снимается), «реабилитированный больной», выходя из зоны статуса «инвалид», также автоматически утрачивает Индивидуальную программу реабилитации и абилитации, т. е. вместе со статусом утрачивается механизм возможного получения реабилитационных услуг от соответствующих учреждений [10]. Важно отметить, что в учреждениях, оказывающих лечебно-профилактическую помощь (ОЛПП), где собственно первично возникает больной (например, вследствие инфаркта, гипертонической болезни, злокачественных новообразований, травм, из-за которых может развиться инвалидизация, либо других инвалидизирующих причин), специалистыпсихологи на данном этапе - явление редкое! В то время как исследования адаптации больных к ситуации инвалидизирующего заболевания выявили факт потребности в получении психологической помощи именно на первичном этапе возникновения инвалидизирующего заболевания [15].

Значимость первичной коррекции и профилактики дезадаптивных проявлений «Внутренней картины инвалидности» до наступления законодательно установленной инвалидизации на этапе лечения больных очевидна. Данный подход является основой предотвращения множественных случаев «психологического ухода» в болезнь и инвалидность, и необоснованных отождествлений с инвалидным сообществом в противовес активной жизненной позиции, формируемой в рамках психологической реабилитации, направленной на преодоление фрустрирующих последствий заболевания (где это, конечно, возможно) вне зоны инвалидности. Изложенное позволяет констатировать необходимость включения психологов в лечебно-диагностический процесс учреждений, оказывающих лечебно-профилактическую помощь больным и особенно инвалидам, для оценки их реабилитационного потенциала и активизации системы психологических ресурсов с целью повышения приверженности к реабилитации.

Также исследование выявило однозначную необходимость психологической коррекции дезадаптивных проявлений «Внутренней картины инвалидности» у лиц, утративших инвалидность вследствие полной реабилитации. Данная категория больных является наиболее «психологически» уязвимой вследствие утраты социального статуса и кризисного «лиминального» состояния [19], требующего активизации всей структуры реабилитационного потенциала, психологический компонент которого, на наш взгляд, в данном случае является наиважнейшим $[13,15]$. Однако реализация реабилитации на данном этапе не имеет законодательной основы и базируется на индивидуальном уровне возможности обеспечения больных реабилитационной 
поддержкой в зависимости от степени сформированности системы реабилитации в том или ином учреждении. В данном случае решение проблемы могут обеспечить целевые мероприятия по коррекции «Внутренней картины инвалидности» и формированию приверженности к реабилитации у больных, утративших статус «инвалид», в «переходный» период в рамках концепции «Школ социальной жизни», организуемых как комплексные консультативнокоррекционные центры на базе Главных Бюро медико-социальной экспертизы субъектов РФ [14].

В порядке обобщения теоретических и эмпирических данных, представленных в настоящей статье, можно сделать следующие выводы:

1. Предложенная модель системы психологической реабилитации в контексте концепции «Внутренней картины инвалидности» интегрирует в своей структуре многокомпонентное содержание (нормативно-правовое, теоретико-методологическое, организационно-методологическое и организационно-процессуальное), обеспечивающее основные цели, задачи, принципы и критерии положительного исхода реабилитации больных, находящихся на различных этапах инвалидизирующих заболеваний.

2. Основными методологическими базовыми принципами организации и совершенствования системы психологической реабилитации больных, предложенными в модели, являются: научная обоснованность, раннее начало (включение) больного в реабилитационный процесс, преемственность (обеспечиваемая межведомственным взаимодействием), непрерывность и комплексность реабилитационного воздействия с учетом индивидуального подхода, этики и деонтологии.

3. Основной целью психологической реабилитации лиц на различных этапах инвалидизирующего заболевания является повышение приверженности к реабилитации в целом, что позволяет констатировать важность реализации оценки дезадаптивных проявлений внутренней картины инвалидности, своевременной профилактики и коррекции выявленных «маркеров», характеризующих неблагоприятный реабилитационный прогноз с учетом их реализации на первичном, вторичном и третичном уровнях.

4. Содержательные аспекты коррекционного и профилактического психологического воздействия необходимо фокусировать на значимых ресурсных личностных диспозициях (личностном реабилитационном потенциале), в зависимости от структуры и степени сформированности которого необходимо формировать реабилитационные мероприятия в виде индвидуальной работы (психологического консультирования, психологической коррекции), а также групповых форм психологической работы (тренинги, работа с семьей). 

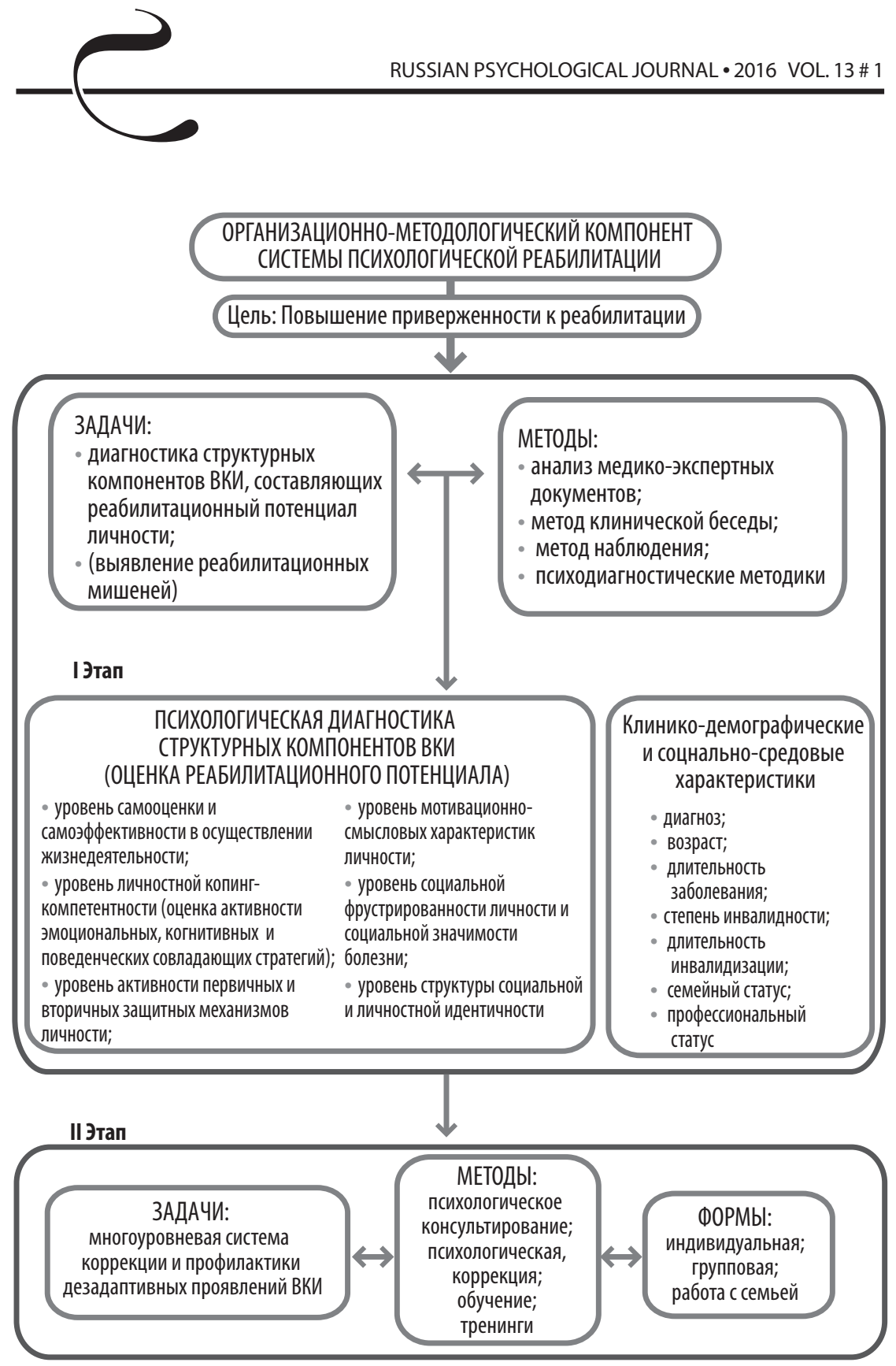

Рисунок 5. Организационно-методологический компонент системы психологической реабилитации в контексте концепции «Внутренней картины инвалидности» 


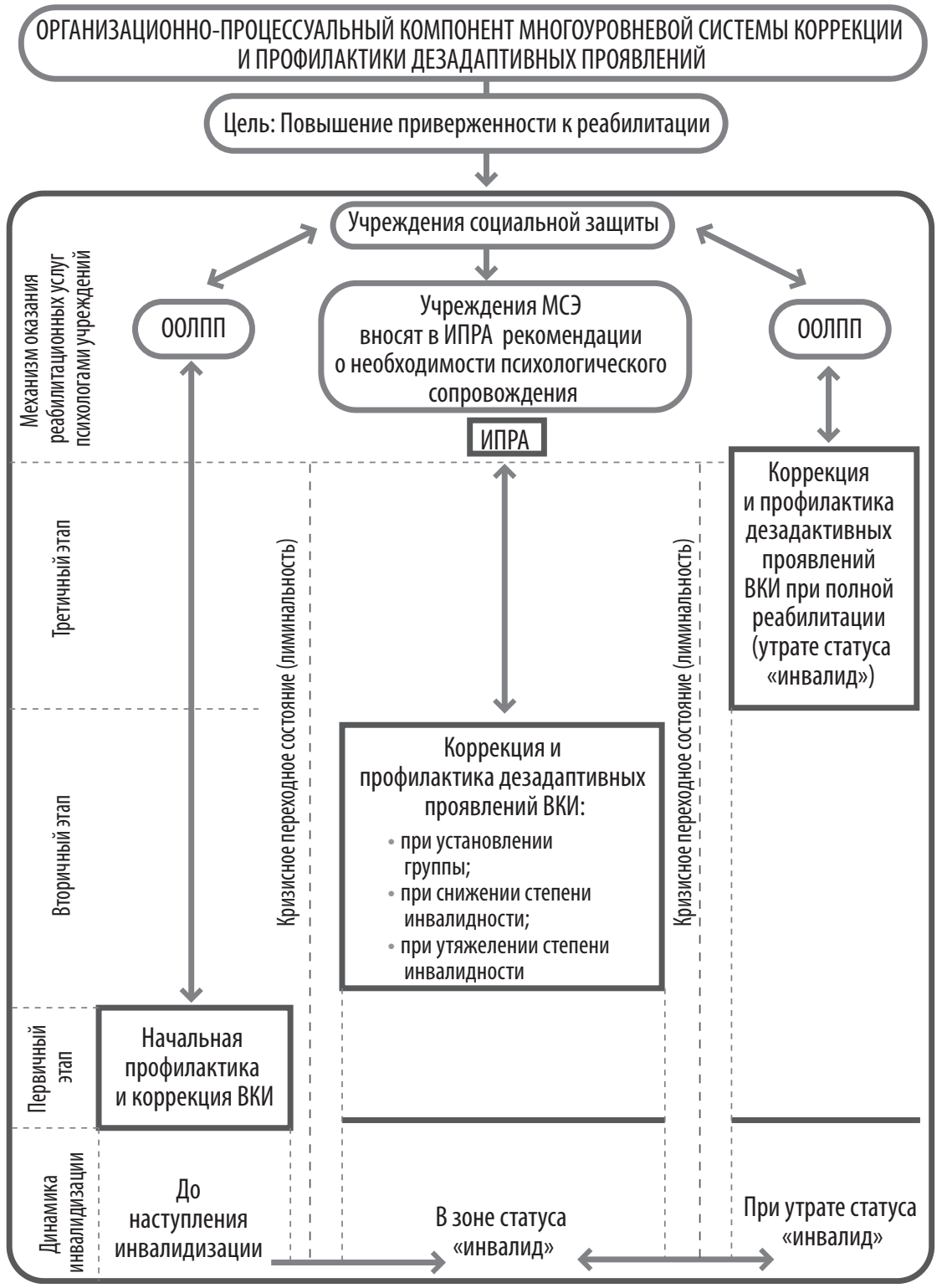

Рисунок 6. Организационно-процессуальный компонент системы психологической реабилитации (этапной коррекции и профилактики дезадаптивных проявлений ВКИ) 
5. Эффективная реализация многокомпонентной модели реабилитации больных на различных этапах инвалидизирующего заболевания на межведомственной основе (в учреждениях, оказывающих лечебнопрофилактическую помощь, в учреждениях, подведомственных системе социальной защиты населения и др.) требует, по нашему мнению, пересмотра нормативно-правового регулирования в области стандартов оказания услуг больным в отношении обязательного психологического сопровождения (диагностического, профилактического, коррекционного).

Изложенные выводы позволяют констатировать следующее: повышение качества оказания психологической реабилитации больным на различных этапах инвалидизирующего заболевания на межведомственной основе возможно посредством включения современных практик эффективной организации реабилитационного процесса с учетом совокупности организационнометодологических принципов и компонентов, в предлагаемой модели системы психологической реабилитации в контексте концепции «Внутренней картины инвалидности».

\section{Литература}

1. Бегма И. В., Морозова Е. В., Жукова Е. В. Исследование жизненной стратегии больных сахарным диабетом как основа их успешной комплексной реабилитации // Вестник всероссийского общества специалистов по медико-социальной экспертизе, реабилитации и реабилитационной индустрии. - 2015. - № 1. - С. 102-107.

2. Волкова И. П., Королева Н. Н. Теоретико-методологические и организационные основы психологического сопровождения реабилитации инвалидов по зрению // Известия Российского государственного педагогического университета им. А. И. Герцена. - 2005. - Т. 5. - № 12. С. 95-108.

3. Зинченко Ю. П., Первичко Е. И., Тхостов А. Ш. Методологические основы и задачи психологической реабилитации онкологических больных // Вестник восстановительной медицины. - 2014. - № 5. - С. 31-42.

4. Каладзе Н. Н., Хан М. А., Кармазина И. В., Мельцева Е. М. Многолетний опыт реабилитации детей с онкогематологическими заболеваниями на Евпаторийском курорте // Материалы международного конгресса «Реабилитация и санаторно-курортное лечение 2012». - М., 2012. С. 51-52.

5. Кантемирова Р. К., Фидарова З. Д., Сердюков С. В., Кабулова А. З. Оценка эффективности реабилитации при ишемической болезни сердца у инвалидов пожилого возраста, перенесших хирургическую реваскуляри- 
зацию миокарда, с учетом положений международной классификации функционирования // Комплексные проблемы сердечно-сосудистых заболеваний. - Кемерово, 2014. - № 3. - С. 51-52.

6. Лазарева Е. Ю., Николаев Е. Л. Психотерапия и психологическая помощь больным сердечно-сосудистыми заболеваниями // Вестник психиатрии и психологии Чувашии. - 2015. - Т. 11. - № 1. - С. 57-77.

7. ЛебедеваЛ.Д. Восстановительная арт-терапия эмоциональных состояний онкобольных // Клиническая и специальная психология. - 2012. - № 3. URL: http: // psyjournals.ru / psyclin / 2012 / n3 / 55195.shtml

8. Львова Н. В., Костерева Л. И. Применение интегративного подхода в психологической реабилитации женщин с раком молочной железы // Вестник специалистов по медико-социальной экспертизе. - 2015. № 1. - C. 65-72.

9. Морозова Е. В. Внутренняя картина инвалидности (генез, структура, функции, свойства) // Медико-социальная экспертиза и реабилитация. 2008. - № 1. - С. 42-46.

10. Морозова Е. В. Парадоксы и факторы детерминации социальных и личностных конфликтов, связанных со статусом «инвалид» // Клиническая и медицинская психология: исследования, обучение, практика:электрон. науч. журн. - 2013. - № 1 (1). URL: http: // medpsy.ru / climp

11. Морозова E. В. Совладающее поведение как проявление общей адаптационной реакции на получение инвалидности // Медицинский вестник Юга России. - 2014. - № 2. - С. 128-133.

12. Морозова E. В. Специфика внутренней картины инвалидности в зависимости от уровня социальной фрустрированности личности // Ученые записки Российского Государственного социального университета. 2015. - № 2. - С. 47-49.

13. Морозова Е. В. Субъективное отношение к инвалидности как основной фактор социально-психологической адаптации личности // Вестник Всероссийского Общества специалистов по медико-социальной экспертизе, реабилитации и реабилитационной индустрии. - 2009. № 2. - С. 144-150.

14. Морозова Е. В. Школа социальной жизни - как инновационная реабилитационная технология // Вестник Всероссийского общества специалистов по медико-социальной экспертизе, реабилитации и реабилитационной индустрии. - 2012. - № 3. - С. 19-27.

15. Морозова Е. В., Шмелева С. В. Влияние субъективного отношения к инвалидности на приверженность к реабилитации // Ученые записки Российского Государственного социального университета. - 2011. № 7. - С. 58-62. 
16. Платонов К. К. Структура и развитие личности. - М.: Наука, 1986. $256 \mathrm{c}$.

17. Рыбников В. Ю., Морозова Е. В. Структурно-динамическая модель внутренней картины инвалидности в контексте психологической реабилитации // Вестник психотерапии. - 2016. - № 57 (62). - С. 113-133.

18. Сухова Е. В. Медико-психологическая реабилитация больных хроническими заболеваниями легких: дисс. ... д. мед. наук. - Самара, 2003.

19. Урываев В. А., Морозова Е. В. Феномены лиминальности в структуре переживания инвалида // Сибирский психологический журнал. - 2013. № 4 (50). - С. 63-69.

20. Шенцева Н. Н., Давыдова А. Ю. Описательная модель социальнопсихологической реабилитации группы «молодых людей - инвалидов» // Научный диалог. - 2013. - № 14. - С. 85-95.

21. Chair S. Y., Chan S. W.-C., Thompson D. R., Leung K.-P., Ng S. K.-Ch., Choi K. Ch. Long-term effect of motivational interviewing on clinical and psychological outcomes and health-related quality of life in cardiac rehabilitation patients with poor motivation in Hong Kong: a randomized controlled trial // Clinical Rehabilitation. - 2013. - V. 27. - 12. - pp. 1107-1117.

22. Janssen H., Ada L., Bernhardt J., McElduff P., Pollack M., Nilsson M., Spratt N. Physical, cognitive and social activity levels of stroke patients undergoing rehabilitation within a mixed rehabilitation unit // Clinical Rehabilitation. 2014. - V. 28. - 1. - pp. 91-101.

23. Kosciulek John F. Research Applications of the Longitudinal Study of the Vocational Rehabilitation Services // Program Rehabilitation Counseling Bulletin. - 2004. doi:10.1177 / 00343552040470030601

24. Mpofu E., Conyers L. M. A Representational Theory Perspective of Minority Status and People with Disabilities: Implications for Rehabilitation Education and Practice // Rehabilitation Counseling Bulletin. - 2004. doi:10.1177 / 00343552040470030301

25. Rosenstock I. M., Strecher V. J., Becker M. H. Social learning theory and the Health Belief Model // Health. Educ. Q. - 1988. - V. 15 (2). - pp. 175-183.

26. Rozema H., Völlink T., Lechner L. The role of illness representations in coping and health of patients treated for breast cancer // Psychooncology. - 2009. V. 18 (8). - pp. 849-857.

27. Teasell R., Foley N., Salter K. [et al.] Evidence-based review of stroke rehabilitation: executive summary, 12th edition // Top Stroke Rehabil. 2009. - V. 16. - pp. 463-488.

28. Tyson S. F., Burton L., McGovern A. The effect of a structured programme to increase patient activity during inpatient stroke rehabilitation: a Phase I cohort study // Clinical Rehabilitation. - 2016. - V. 30. - 2. - pp. 191-198. 
29. Wagner C. C., McMahon B. T. Motivational Interviewing and Rehabilitation Counseling Practice // Rehabilitation Counseling Bulletin. - 2004. doi:10.1177/ 00343552040470030401

30. Weinstein N. D. Testing four competing theories of health-protective behavior // Health. Psychology. - 1993. - V. 12. - pp. 324-333. 